fluctuations of greater amplitude were found in the thalamus-subthalamus, but these changes were not statistically significant (Table 1). A daily noradrenaline rhythm has been demonstrated in the lateral hypothal amus of the cat ${ }^{10}$. In the present experiment, the region designated thalamus-subthalamus contained the lateral hypothalamic area, as well as the thalamus. It is possible that a daily rhythm exists in lateral hypothalamic noradrenaline and that the rhythm was obscured in the present study because the hypothalamic tissue was diluted with relatively large amounts of thalamus. The noradrenaline concentrations in the rat midbrain and striatum did not vary during the day; similar findings have been reported in the cat ${ }^{10}$.

The neuroanatomic structures responsible for hypothalamic noradrenaline rhythms are not known, nor are the biochemical mechanisms which generate them clear. The increased concentration of the neurotransmitter during the dark period could be caused by enhanced noradrenaline synthesis, decreased release of the amine, or a decrease in its rate of intracellular metabolism. It seems likely that the amount of hypothalamic noradrenaline which can be liberated by a drug also depends on the time of day that the drug is administered. If this is true, it is possible that psychotropic drugs (such as amphetamine) which produce their effects by releasing brain noradrenaline may show time-dependent variations in potency.

We thank Dr Julius Axelrod for helpful discussions, and Mrs Helen Hunt for technical assistance. These studies were supported by the US Public Health Service.

James ManshaRdT*

RICHARD J. WURTMAN

Department of Nutrition and Food Science,

Massachusetts Institute of Technology,

Cambridge, Massachusetts.

Received November 13; revised December 14, 1987.

* Medical student at Baylor University College of Medicine, Texas Medical Center, Houston, Texas.

1 Wurtman, R. J., and Axelrod, J., Life Sci., 5, 665 (1966).

2 Hokfelt, B., Acta Physiol. Scand., 25, Suppl. 92 (1951).

'Wurtman, R. J., Catecholamines (Little Brown and Co, Boston, 1966).

- Bertler, A., and Rosengren, E., Acta Physiol. Scand., 47, 350 (1959).

- Carlsson, A., Falck, B., and Hillarp, N. A., Acta Physiol. Scand., 56, suppl. 196 (1962).

- Dahistrom, A., and Fuxe, K., Acta Physiol. Scand., 62. suppl, 232 (1964).

; Glowinski, J., and Iversen, L. I., J. Neurochem. 13, 655 (1966).

* Vogt, M., J. Physiol.,123, 451 (1954).

Von Euler, U. S., and Lishajko, F., Acta Physiol. Scand., 51, 348 (1961).

in Reis. D. J., and Wurtman, R. J., Life, Sei. (in the press).

\section{Thermoregulation in Tortoises}

Asthough reptiles in a laboratory cage may show feeble powers of thermoregulation, it is now known that, when active in natural conditions, their body temperature is often regulated by behavioural means at a thermal level higher than that of many mammals ${ }^{1}$. Tortoises are no exception and sun themselves when the air is cool. Experiments on young desert tortoises, Testudo sulcato Miller ( $=T$. calcarata Schn.), have shown that water loss by evaporation increases greatly in dry air at tempera. tures above $40^{\circ}-41^{\circ}$ C. At ambient temperatures of $55^{\circ} \mathrm{C}$ the body temperature rises rapidly to about $40.5^{\circ} \mathrm{C}$, at which level it is maintained by copious salivation which wets the head, neck and front legs. Although they do not usually take water when supplied with green food, these tortoises drink deeply after such experiments.

\section{J. L. Cloudsley-Thompson}

Department of Zoology,

University of Khartoum,

Sudan.

Recelved January 2, 1968.

1 Schmidt-Nielsen, K., and Dawson, W. K., Adaptation to the Environment Handbook of Physiology, Sect. 4, 467 (Amer. Physiol. Soc., 1964).

\section{Application of Laser Interferometry to Physiological Studies of Excitable Tissues}

INTERFEROMETRIC techniques offer a sensitive means of measuring small displacements, film thickness and changes in refractive index. By applying interferometry to studies of excitation processes, Kayushin and Lyudkovskaya ${ }^{1,2}$ and Lyudkovskaya ${ }^{3}$ reported that they had detected small movements of frog sciatic nerve in association with excitation. This communication describes a technique of applying laser interferometry to the investigation of various excitable tissues; we have tried to detect small movements accompanying the action potentials of fresh water algae (Nitella) and frog and lobster nerve trunks.

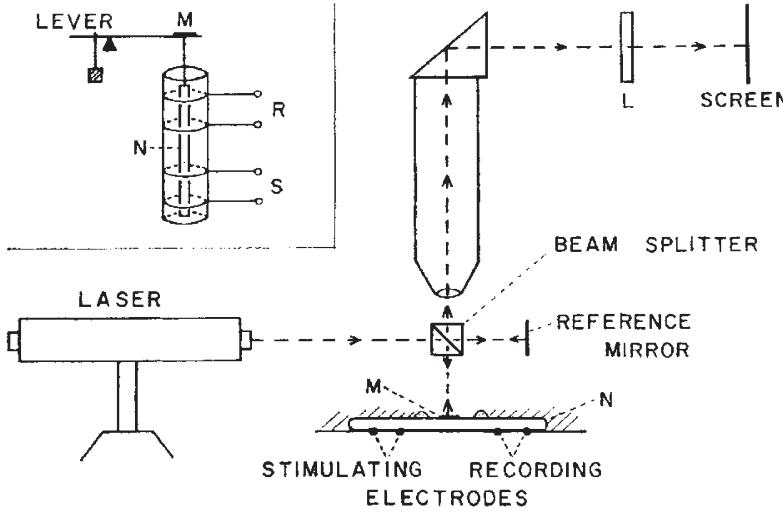

Fig. 1. Schematic diagram showing the interferonetry set-up used to examine excitable tissue for the presence of small movements associated with the production of action potentials. $M$ represents a small mirror placed on the surface of a Nitella internode or a nerve trunk $(N)$. Two 'Vaseline' partitions were used to separate the middle section of the tissue from the lateral portions where the platinum wire stimulating and record. ing electrodes were placed. I represents a cylindrical lens ised to focus the interference pattern on to the screen of the oscilloscope used for recording the action potential. The inset illustrates the technique used to examine changes in the length of an excitable tissue $(N)$ in response to electric stimulation. Stimulating $(S)$ and recording $(R)$ electrodes were made of rings of platinum wire (separated by approximately $10 \mathrm{~mm}$ ) placed near the wall of the cylindrical 'Lucite' chamber (filled with sea
water diluted by a factor of 2,000 ).

A helium-neon gas laser (Perkin-Elmer, model 5200) served as a source of continuous, coherent, plane-polarized light $(0 \cdot 6328 \mu$ wavelength). An interference objective attachment (W. Watson and Sons, England) was modified by removing the condenser lens system and was fitted to a standard monocular microscope. The experimental set-up is illustrated schematically in Fig. 1. The laser beam was split in two by means of a half-silvered mirror. Interference was obtained between one portion of the beam reflected back from a reference surface mirror to the half-silvered mirror and the other part of the beam reflected from a small surface mirror attached to the biological preparation. A prism at the top of the microscope tube and a cylindrical lens were used to focus the resulting interference pattern onto the upper half of a cathode ray oscilloscope screen. In this manner, the interference pattern and the electrical response of the tissue to stimulation (displayed on the lower half of the oscilloscope screen with a standing beam) could be recorded simultaneously on moving photographic film.

In one series of experiments, the small surface mirror $\left(0.5 \mathrm{~mm}^{2}\right)$ was placed directly on the (moist) surface of a Nitella axillaris internode, frog sciatic nerve or lobster circumoesophageal connective (Fig. 1). These excitable tissues were mounted horizontally in a 'Lucite' chamber provided with two pairs of platinum electrodes (one pair 